\title{
Latissimus dorsi myocutaneous extended flap in the reconstruction of large chest wall defects after extensive resections in breast pathology
}

\author{
Francisco Miguel Said-Lemus ${ }^{*}$, Guillermo G. Peralta-Castillo², Jorge A. Salazar-Andrade², \\ Antonio Maffuz-Aziz², Santiago Sherwell-Cabello² and Santiago Rodríguez-Cuevas ${ }^{2}$
}

${ }^{1}$ Department of Plastic and Reconstructive Surgery; ${ }^{2}$ Department of Breast Surgery, Instituto de Enfermedades de la Mama FUCAM. Ciudad de México, Mexico

\begin{abstract}
Locally advanced breast cancer remains a major problem in developing countries and it is a common presentation of breast cancer worldwide. In our country, $45 \%$ of all breast cancer cases are diagnosed at this stage. The cutaneous coverage of the chest wall after extensive resection in patients with breast cancer has always been a challenge for the surgical team, and the latissimus dorsi flap is widely used at the reconstruction of the chest wall. With the classic technique, the size of the skin flap usually does not exceed $10 \mathrm{~cm}$. For this reason, in our institute we have implemented the extended latissimus dorsi flap to cover large defects of the chest wall. A retrospective study was performed in which all patients treated with extended latissimus dorsi flap were included over a period of 5 years. A total of 30 patients have been reconstructed with a latissimus dorsi muscle-skin flap, 15 of them with the extended technique, achieving tumor resections up to $30 \mathrm{~cm}$. The mean age was 42.6 years. With a mean follow-up of 15.8 months and a low rate of complications requiring reoperation (6.6\%). This technique is reproducible and it can be performed in one surgery, and it may be considered as a reconstruction technique for partial or total aesthetical reconstruction, with palliative or curative purposes. We are convinced that the success of this technique depends on the proper selection of patients and a coordinated multidisciplinary treatment between breast and plastic surgeons.
\end{abstract}

Key words: Breast. Skin coverage. Breast reconstruction. Myo-cutaneous flap. Latissimus dorsi.

Correspondence:

${ }^{\star}$ F.M. Said-Lemus

E-mail: fmsaid@ hotmail.com
Date of reception: 01-06-2017

Date of acceptance: 10-10-2017

DOI: 10.24875/j.gamo.M18000146
Available online: 24-02-2018 Gac Mex Oncol. 2017;16(6):315-320

www.gamo-smeo.com 1665-9201 / C 2017 Sociedad Mexicana de Oncología. Published by Permanyer México. This is an Open Access article under the terms of the CC BY-NC-ND license (http://creativecommons.org/licenses/by-nc-nd/4.0/). 


\section{Introduction}

Breast cancer has a great impact on women's health. It is the most common type of cancer worldwide, with more than one million new cases every year. In spite of an increased incidence, mortality related to this condition has decreased in developed countries ${ }^{1,2}$. The probability for developing invasive cancer in women is $12.03 \%$ during their lifetime (1 in every 8 women) ${ }^{3}$. Annually, approximately 178,480 women are diagnosed with invasive breast cancer in the United States, which represents approximately $32 \%$ of all cases of cancer in women $^{4,5}$. In Mexico, this condition occupies the first place as malignancy-related cause of death since 2006, ousting cervical cancer from this position ${ }^{6}$.

The American Joint Commission on Cancer (AJCC) published the last revision of its staging system in $2016^{7}$, which is based on three parameters: tumor size $(\mathrm{T})$, lymph node status $(\mathrm{N})$, and presence of metastasis (M). In this system, patients are clinically (c) or pathologically (p) assigned to a stage (TNM). In general terms, the higher the grade is, the worse the prognosis will be ${ }^{8}$. Unfortunately, the most advanced stages remain a common presentation form in developing countries, and less so in developed countries ${ }^{9}$. In the USA, it accounts for $5-10 \%$ of newly diagnosed carcinomas, whereas in our country, according to data of the Institute of Breast Diseases, it accounts for $45 \%$ of cases at diagnosis ${ }^{10,11}$. This includes patients with large tumors with fixation to the chest wall or skin ulceration. It is important to consider that a percentage of these patients are young women (younger than 40 years), who are carriers of voluminous, ulcerated tumors, or with fixation to the chest wall ${ }^{12-14}$.

In many locally advanced breast cancer cases, initial radical surgery may be indicated, since skin and/or chest wall involvement can be extensive, have ulceration and bleeding, or progress on neoadjuvant treatment. It is for this reason that in some cases extensive resections and reconstructive surgery procedures are required in order to cover vital structures and to ensure adequate wound healing. Some indications include: radionecrosis, tumors affecting the fascia, muscle and occasionally the ribs, and tumors with important bleeding $^{15,16}$. Resection and skin coverage can also improve the quality of life of patients with advanced breast cancer, since it provides a palliative effect in tumors with extensive necrosis ${ }^{17}$.

Chest wall reconstruction after extensive resection has always been a challenge for the surgical team. There are different techniques described for this purpose, each one of them indicated according to the requirements of the defect to be corrected. The selection of such technique mainly depends on the size of the wound and type of tissue. In addition, patient prognosis should always be considered in decision making. The main objective is to reestablish coverage and protection of intrathoracic structures and, sometimes, with an acceptable esthetical result ${ }^{18}$.

The latissimus dorsi flap has been widely used for chest wall reconstruction since 1897, and was initially described by the Italian surgeon Tasini. One of the first fasciocutaneous flaps of the thoracoabdominal ipsilateral area was described by Tai in 1974, and it was irrigated by the superior epigastric artery ${ }^{19}$. Subsequently, and after better understanding of the anterior and lateral abdominal wall vascular anatomy, flaps with subcostal, intercostal or lumbar irrigation were described, and by the mid 80 's, muscle and skin-muscle flaps became the gold standard for chest wall reconstruction. ${ }^{20,21}$

Latissimus dorsi flap is widely used in chest wall reconstruction mainly in breast cancer patients ${ }^{22}$. The thoracodorsal vessels normally provide the blood supply of the pedicle for the latissimus dorsi flap, usually allowing for a large muscle portion to be mobilized; however, the size of the skin portion is often not too large, and the skills to closure the donor site dictates the size of the flap; therefore, the usual size of the skin is generally not larger than $10 \mathrm{~cm}$ in the described classic techniques ${ }^{17,23,24}$. For this reason, the classic technique has been modified at the FUCAM Institute of Breast Diseases in order to obtain larger skin flaps that allow for large chest wall defects to be reconstructed after breast cancer-related resections.

\section{Material and methods}

A retrospective study was carried out using the prospective database of the FUCAM Institute of Breast Diseases of all identified cases of reconstruction with latissimus dorsi extended flap from January 2011 through June 2016. Assessments on patient demographics, tumor size and diagnosis, as well as the rate and type of complications are presented. In addition, the employed surgical technique is described and analyzed.

\section{Preoperative planning}

The latissimus dorsi extended flap is intended to provide skin coverage with or without breast reconstruction criteria, without the need to demarcate a skin 
bridge between the dorsal region and the chest anterior wall.

The first step is the marking of the patient by the surgeon who will perform the resection together with the surgeon in charge of the reconstruction in order to identify the limits of the resection zone, which will depend on the extension of the pathology to be treated (Fig. 1-A). This marking is made using the same criteria than for conventional latissimus dorsi flap with the anatomic variation that the lower lateral border of the defect will become the flap distant portion, since blood supply is determined by perforating arteries, the perforator vessels of which project to the anterior portion, which results in extended skin islands of up to $30 \mathrm{~cm}$ long at their longest axis (Fig. 1-B, C).

\section{Surgical technique}

Once the oncologic resection is concluded, the defect to be reconstructed is evaluated. The patient is placed in the lateral decubitus position and final marking of the skin island is performed, where the lower lateral border of the defect will become the anterior vertex of the skin island.

The skin island dissection proceeds until the plane of the latissimus dorsi muscle fascia is reached, where the superior portion of this flap is dissected and freed in the lateral to medial direction towards the thoracic spine apophyses and the lateral and inferior edge of the scapula until the axillary portion is reached. This way, latissimus dorsi muscle vision is obtained from above the skin island. The same is performed on the inferior border of the island, only to take the inferior edge of the latissimus dorsi, with a muscle extension of between 5 and $7 \mathrm{~cm}$. Once the entire extension of the latissimus dorsi is freed, its dissection is carried out from the medial to lateral direction, always under observation and caution only to dissect this muscle, especially respecting deep muscle planes. The upper portion of the chest lateral flap is then freed, exposing the lateral side, which enables the lifting of the flap to be carried out without a skin pocket, a usual problem of the traditional technique (Fig. 1-D).

The dissection is continued, with insertions following until the axillary edge. The emergence of the thoraco-dorsal artery can be observed on the posterior side of the flap, which is where the dissection concludes, with this point being taken as an axis for rotation of the entire flap. The rotation movement is carried out in the posterior to anterior direction for skin coverage projection (Fig. 1-E, F).
The dorsal region reconstruction is characterized by the superior flap advancement following an inferior-medial trajectory, thus achieving a conventional result for the latissimus dorsi flap.

The patient is then rotated to the ventral decubitus position. Donor site closure is carried out by advancement and rotation of the superior flap in the anterior and inferior direction trying to reduce the donor area and making the closure of the skin island territory, thus leaving a single result in continuity to the skin island, with a single drainage placed in the dorsal region and other by counter-aperture in the anterior region (Fig. 1-G, H).

\section{Results}

Over a 5-year period, a total of 15 patients with advanced breast cancer or malignant phyllodes tumor (Fig. 2 and 3) were treated with radical and total mastectomy, respectively, with latissimus dorsi myocutaneous extended flap reconstruction. Mean age was 42.6 years (range: 29 - 58 years) (Table 1). Tumor dimension ranged from 5.3 to $30 \mathrm{~cm}$, with a mean of $14.8 \mathrm{~cm}$ at the longest diameter (Table 1). Average follow-up was 15.8 months (range: 1-42 months) (Table 2).

The main indication for surgery was locally advanced breast cancer in 73\% (11 patients), with ductal infiltrating carcinoma being the predominant diagnosis $(66 \%)$, followed by malignant phyllodes tumor $(26 \%)$ and, finally, by a case of metaplastic carcinoma.

In no case was it necessary for a rib cage resection to be performed, and during follow-up, a rate of local complications of $33 \%$ (5 out of 15 patients) was found, with two patients experiencing more than one complication, mainly partial necrosis of the flap or dehiscence of some border. No flap total loss was reported. Most complications were minor and limited, with $60 \%$ being solved in the office (Table 1), and only one patient requiring reoperation (6.6\%). All patients had adequate and satisfactory chest wall coverage, with no death being associated with the procedure.

\section{Discussion and conclusions}

The first reports on the prognosis of locally advanced carcinoma were described by Haagensen and Scout in 1940. Using modified radical mastectomy as single therapeutic measure, there was recurrence in $46 \%$ and 5 -year survival was only $6 \%{ }^{25}$. In view of this experience, locally advanced carcinoma was initially classified 

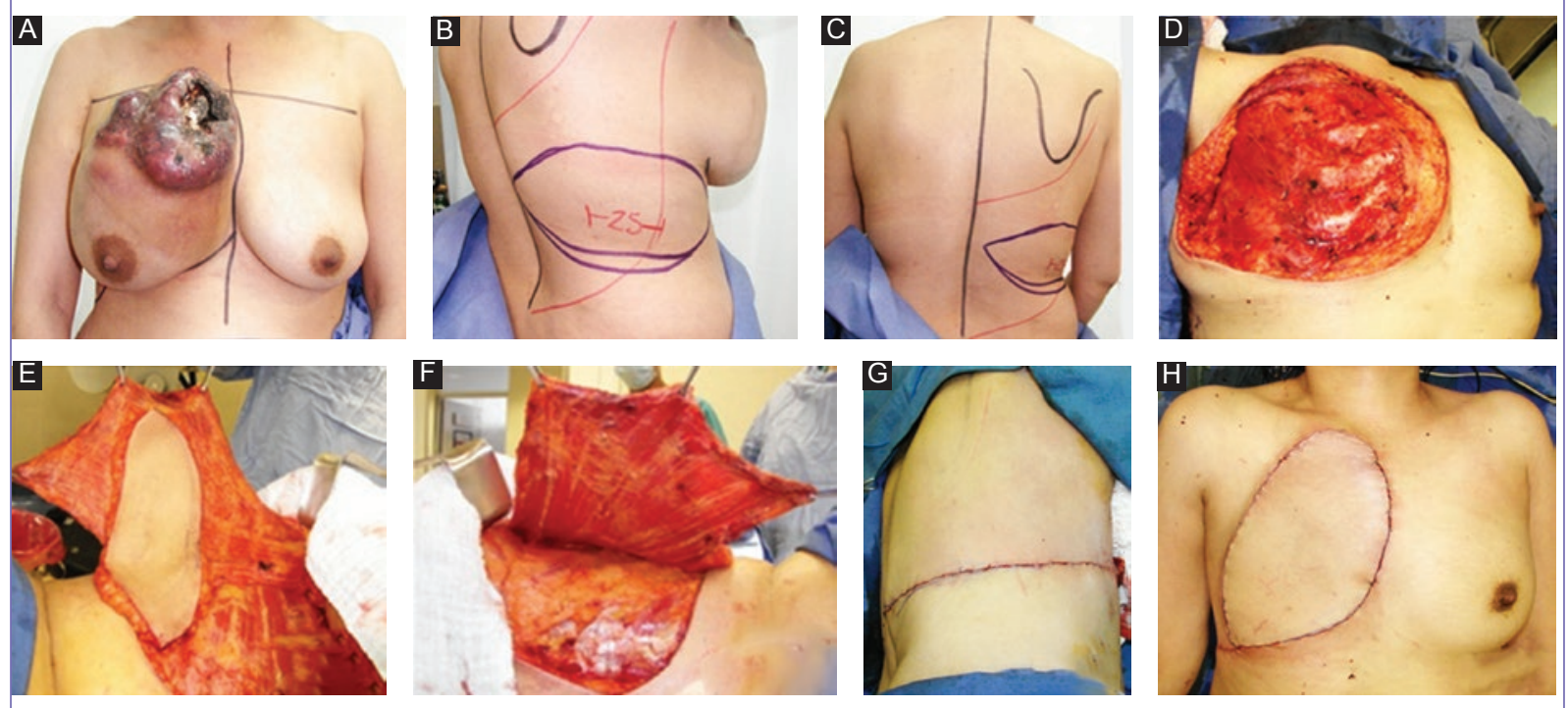

Figure 1. A, B and C: anterior, lateral and posterior pre-surgical marking. D: initial defect to be covered. E: latissimus dorsi release and dissection. G: lateral and posterior closure. H: anterior defect closure.
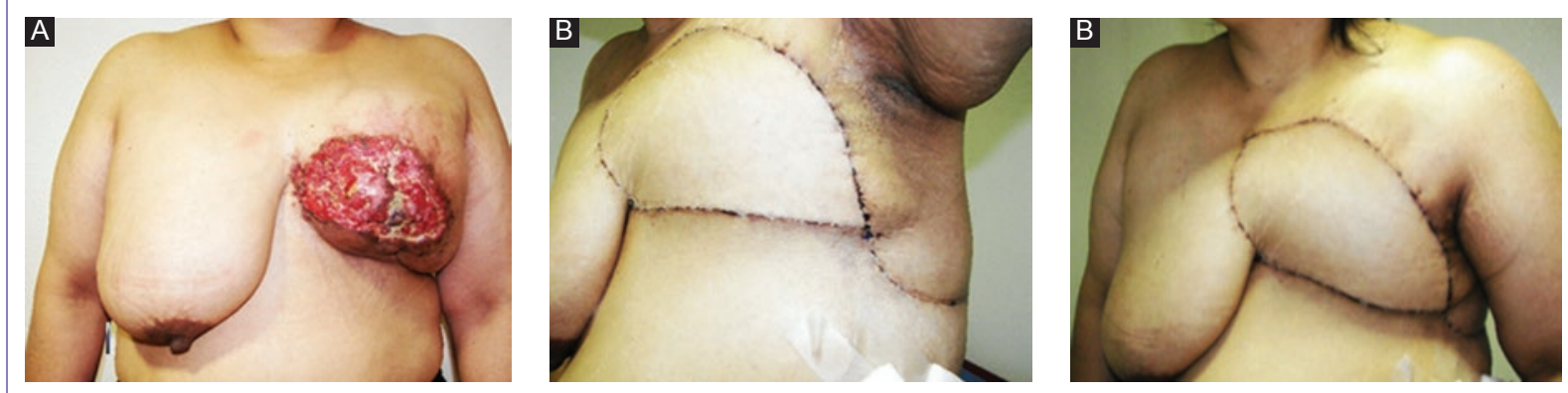

Figure 2. Patient with stage IIIB infiltrating ductal carcinoma.
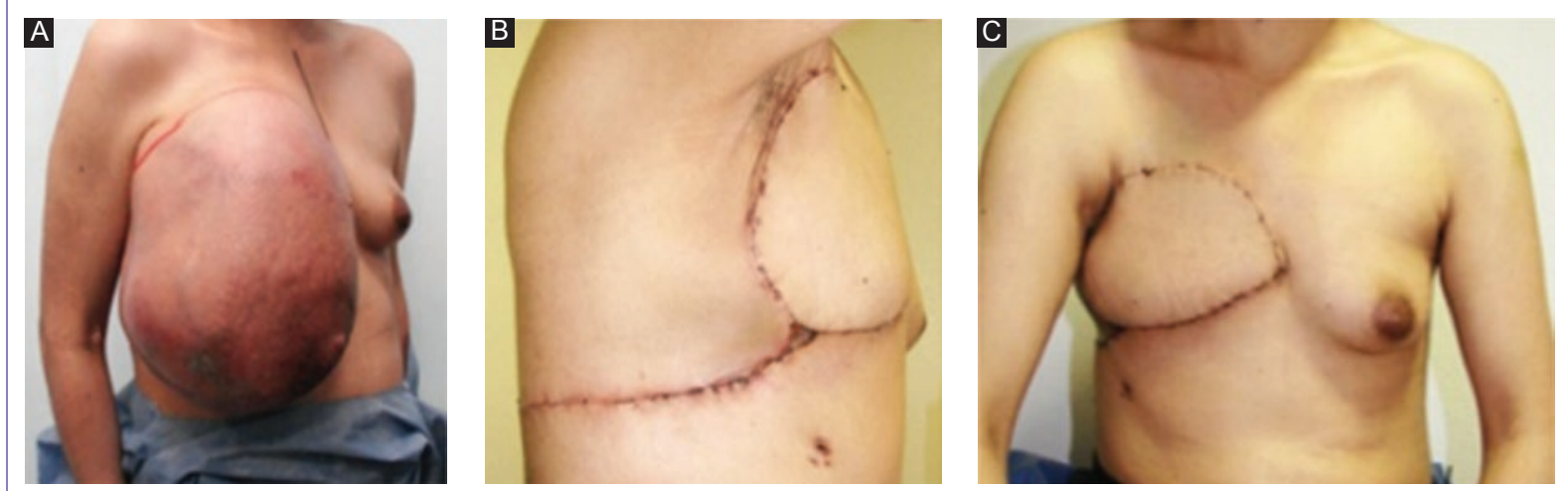

Figure 3. Patient with malignant phyllodes tumor. A: pre-surgery. B: post-surgery.

as inoperable when there were complications such as extensive skin edema or satellite lesions, intercostal nodules, edema of the arm, supraclavicular metastasis or inflammatory cancer, ulceration, edema of the skin, 
Table 1. Age, tumor characteristics and complications

\begin{tabular}{|c|c|c|c|c|c|c|c|}
\hline & Age & Diagnosis & Stage & Breast & Tumor size & Complications & \\
\hline 1 & 37 & IDC & T3 N3 M0 & $\mathrm{R}$ & $12 \times 15 \mathrm{~cm}$ & No & $\stackrel{\infty}{\infty}$ \\
\hline 2 & 53 & IDC & T4d N1 M0 & $\mathrm{L}$ & 12.5 & Hematoma & $\frac{0}{1}$ \\
\hline 3 & 58 & IDC & T4b NO MO & $\mathrm{R}$ & $16 \times 12 \mathrm{~cm}$ & \multicolumn{2}{|c|}{ Medial third necrosis/infectio } \\
\hline 4 & 50 & IDC & T4b N2 M0 & $\mathrm{L}$ & $17 \mathrm{~cm}$ & Partial dehiscence & $\frac{\zeta}{d}$ \\
\hline 5 & 37 & IDC & T4d N3 M0 & $\mathrm{R}$ & $30 \mathrm{~cm}^{*}$ & External third necrosis & (C) \\
\hline 6 & 43 & IDC & T4d N3 M1 & L & $13.4 \mathrm{~cm}$ & No & \\
\hline 7 & 46 & MP & - & $\mathrm{L}$ & $23 \times 20 \mathrm{~cm}$ & No & $\frac{\bar{d}}{n}$ \\
\hline 8 & 43 & MP & - & $\mathrm{R}$ & $30 \times 26 \mathrm{~cm}$ & No & $\frac{0}{3}$ \\
\hline 9 & 36 & MP & - & $\mathrm{R}$ & $24 \mathrm{~cm}$ & \multicolumn{2}{|c|}{ Mov. limitation/recurrence } \\
\hline 10 & 33 & IDC & T4b N3 M1 & $\mathrm{L}$ & $6 \times 6 \mathrm{~cm}$ & No & 4 \\
\hline 11 & 29 & MPC & T4d N2 M0 & $\mathrm{R}$ & $8.5 \mathrm{~cm}$ & No & $\frac{0}{n}$ \\
\hline 12 & 44 & IDC & - & $\mathrm{R}$ & $7.5 \times 6.5 \mathrm{~cm}$ & No & $\bar{E}$ \\
\hline 13 & 39 & MP & & L & $6 \times 7 \mathrm{~cm}$ & No & 2 \\
\hline 14 & 54 & IDC & T4d N3 M0 & $\mathrm{L}$ & $5.5 \mathrm{~cm}$ & No & \pm \\
\hline 15 & 37 & IDC & T4b N2 M0 & $\mathrm{R}$ & $5.3 \mathrm{~cm}$ & No & 3 \\
\hline \multicolumn{7}{|c|}{$\begin{array}{l}\text { IDC: invasive ductal carcinoma; MP: malignant phyllodes; MPC: metaplastic carcinoma } \\
\text { *Neoadjuvant chemotherapy, with final size of } 7 \times 5 \mathrm{~cm}+\text { skin edema. }\end{array}$} & 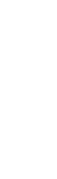 \\
\hline
\end{tabular}

Table 2. Transoperative hemorrhage, surgical time and follow-up

\begin{tabular}{|l|c|}
\hline & Mean \\
\hline Transoperative hemorrhage & $653 \mathrm{cc}(100-1700)$ \\
\hline Surgical time & $255 \mathrm{~min}(180-330)$ \\
\hline Follow-up & 15.8 months (1-42) \\
\hline
\end{tabular}

fixation to pectoralis muscle and bulky axillary adenopathy, which are poor prognosis factors and not necessarily unresectability criteria. The role of reconstructive surgery in the treatment of locally advanced cancer is a topic of increasing interest, owing to the development of innovative techniques that allow for the surgeon to perform broad oncologic resections, which previously would have been regarded as being unfeasible ${ }^{24}$.

Myocutaneous, skin or entirely muscle flaps have been shown to be acceptable alternatives for reconstruction in large defects ${ }^{18}$. The selection of the technique will depend on several factors including the defect size, status of the skin (peri- or post-radiotherapy), the surgeon's skills and available resources (microvascular surgery, skin prostheses, vacuum system, etc.).
In general, surgical initial treatment in patients with locally advanced breast cancer is considered to be contraindicated. However, in the vast majority of our patients it is performed for palliative purposes, usually being therefore reserved to control advanced disease local symptoms (pain, bleeding, ulceration, infection/ necrosis). The latissimus dorsi extended flap has the advantage of being applicable to massive skin defects as large as $40 \mathrm{~cm}$ by replacing all cosmetic units of the breast regardless of the gland volume, which results in scarring free of skin bridges and without apparent physical sequels in the ranges of motion.

We are aware that a broad series of cases is required to appraise the sequels, complications and ideal characteristics of the patients to be treated. With regard to the percentage of postsurgical complications, the vast majority were minor and limited, and probably associated either with clinical conditions or with comorbidities of our patients. In the literature we found complication rates similar to ours; for example, in 2004, Raymond carried out a 10-year review, where he published a reoperation rate of $4 \%$, associated with $16 \%$ of general complications (wound-healing delay, infections or hematomas); on the other hand, Persichetti refers a 
complication rate of $22 \%$, associated with $5 \%$ of reoperations ${ }^{18,26}$.

This technique demands experience in the performance of myocutaneous flaps, but it is reproducible and is carried out in a single surgical intervention; it can be regarded as an excellent option in selected cases for partial or total reconstruction of chest wall large defects, for palliative or, in some cases, curative purposes. With this technique, covering resection areas of up to $40 \mathrm{~cm}$ is possible. We are convinced that success of this technique depends on patient adequate selection and multidisciplinary, experienced treatment, coordinated between breast and plastic surgeons.

\section{Disclosure}

The authors have no personal or financial relationships that might inappropriately influence (bias) on their work.

\section{References}

1. Peto R, Boreham J, Clarke M, et al. UK and USA breast cancer deaths down 25\% in year 2000 at ages 20-69. Lancet. 2000;355(9217):1822.

2. Hortobagyi GN, Buzdar AU. Current status of adjuvant systemic therapy of primary breast cancer progress and controversy. CA Cancer J Clin. 1995;45(4):199-226

3. American Cancer Society. Surveillance and Health Policy Research. American Cancer Society 2009.

4. Weir HK, Thun MJ, Hankey BF, et al. Annual report to the nation on the status of cancer, 1975-2000, featuring the uses of surveillance data for cancer prevention and control. J Natl Cancer Inst. 2003;95(17):1276-99.

5. Jemal A, Siegel R, Ward E, et al. Cancer statistics, 2007. CA Cancer J Clin. 2007;57(1):43-66.

6. Palacio-Mejía LS, Lazcano-Ponce E, Allen-Leigh B, et al. Diferencias regionales en la mortalidad por cáncer de mama y cérvix en México entre 1979 y 2006. Salud Pública Méx. 2009; 51(Supl2):s208-19.
7. Amin MB. https://cancerstaging.org/f. [Online].; 2016 [cited 2017 enero].

8. Edge SB BDCCea. American Joint Committee on Cancer Staging Manual, $7^{\text {th }}$ ed., 2010.

9. Lee MC, Newman LA. Management of patients with locally advanced breast cancer. Surg Clin North Am. 2007; 87:379-98.

10. Consenso Mexicano sobre Diagnóstico y Tratamiento del Cáncer Mamario. Sexta revisión. Gac Mex Oncol. 2015;14(suppl. 2):1.

11. Maffuz-Aziz A, Labastida-Almendaro S, Espejo-Fonseca A, et al. Características clinicopatológicas del cancer de mama en una población de mujeres en México. Cir Cir 2017:85:201-7.

12. Sherwell-Cabello S, Maffuz-Aziz1 A, López-Hernández SN, et al. Young age: The most significant factor contributing to poorer prognosis in mexican women with breast cancer. J Cancer Biol Res. 2015;3(3):1066.

13. Robles-Castillo J, Ruvalcaba-Limón E, Maffuz A, et al. Cáncer de mama en mujeres mexicanas menores de 40 años. Ginecol Obstet Mex. 2011; 79(8):482-8.

14. Olivotto IA, Chua B, Allan SJ, et al. Long-term survival of patients with supraclavicular metastases at diagnosis of breast cancer. J Clin Oncol. 2003;21(5):851-4.

15. Samuels L, Granick MS, Ramasastry S, et al. Reconstruction of radiation-induced chest wall lesions. Ann Plast Surg. 1993 Nov;31(5):399-405.

16. Rouanet $P$, Fabre JM, Tica V, et al. Chest wall reconstruction for radionecrosis after breast carcinoma therapyx. Ann Plast Surg. 1995; 34(5):465-70.

17. Beahm EK, Chang DW. Chest wall reconstruction and advanced disease. Semin Plast Surg. 2004;18(2):117-29.

18. Persichetti P, Tenna S, Cagli B, et al. Extended cutaneous 'thoracoabdominal' flap for large chest wall reconstruction. Ann Plast Surg. 2006;57(2):177-83.

19. Tai $Y$, Hasegawa $H$. A transverse abdominal flap for reconstruction after radical operations for recurrent breast cancer. Plast Reconstr Surg. 1974;53(1):52-4.

20. Brown RG, Vasconez LO, Jurkiewicz MJ. Transverse abdominal flaps and the deep epigastric arcade. Plast Reconstr Surg. 1975;55(4):416-21.

21. Larson DL, McMurtrey MJ. Musculocutaneous flap reconstruction of chest-wall defects: an experience with 50 patients. Plast Reconstr Surg. 1984;73(5):734-40

22. Sodha NR, Azoury SC, Sciortino $C$, et al. The use of acellular dermal matrices in chest wall reconstruction. Plast Reconstr Surg. 2012;130(5 Suppl 2):175S-82S.

23. Arnold PG, Pairolero PC. Chest wall reconstruction: an account of 500 consecutive patients. Plast Reconstr Surg. 1996;98(5):804-10.

24. Munhoz AM, Montag E, Arruda E, et al. Immediate locally advanced breast cancer and chest wall reconstruction: surgical planning and reconstruction strategies with extended v-y latissimus dorsi myocutaneous flap. Plast Reconstr Surg. 2011;127(6):2186-97.

25. Haagensen CD, Stout AP. Carcinoma of the Breast. II-Criteria of Operability. Ann Surg. 1943;118(6):1032-51.

26. Chang RR, Mehrara BJ, Hu QY, et al. Reconstruction of complex oncologic chest wall defects a 10 years experience. Ann Plast Surg. 2004;52(5):471-9. 